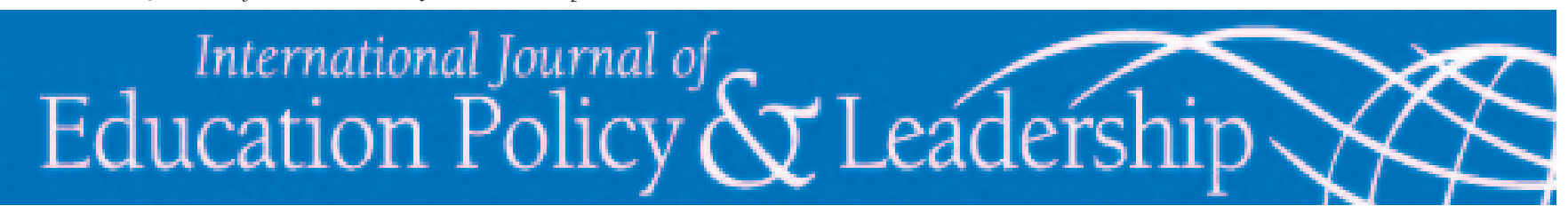

\title{
Melting Pot Influences on Secondary English Curriculum Policy
}

\author{
ALLISON SKERRETT \\ The University of Texas at Austin
}

\begin{abstract}
This article explores how racial, cultural, and linguistic diversity are addressed in secondary English curriculum policy in Massachusetts, U.S.A. Data are analyzed through theories of the sociology of knowledge and the myth of the United States melting pot. Analysis revealed that curriculum policy privileged Eurocentric literature and the English language and adhered to a melting pot ideology. The article considers how the international educational policy movement toward post-standardization may afford greater responsiveness to diversity.
\end{abstract}

Skerrett, A. (2009). Melting Pot Influences on Secondary English Curriculum Policy. International Journal of Education Policy and Leadership 4(11). Retrieved [DATE] from http://www.ijepl.org.

Increasing curriculum standardization in the United States has been, paradoxically, accompanied by growing ethnocultural and linguistic diversity in the student population. These tensions between accelerating student diversity and prescriptive curriculum policies are clearly illustrated in English education (Author, 2009; Barrell, Hammett, Mayher, \& Pradl, 2004; Sloan, 2006). In the United States, English has become an all-encompassing, strongly regulated, and highly tested and tracked subject. All students are required to take some version of an English curriculum, and in this era of high-stakes testing, many must meet externally predetermined benchmarks to progress through, and graduate from, schools. Student diversity will only continue to increase in the United States (Suarez-Orozco, 2001), and the subject of English will retain its central academic and sociocultural roles in schooling (Goodson, 2005). Accordingly, it is vital to explore how ethnocultural and linguistic diversity are being addressed in English curriculum policymaking and to examine the origins of the beliefs that shape these polices. These beliefs, and the subsequent polices that shape the educational practices of schools and teachers, hold high stakes consequences for diverse student populations.

This paper undertakes a content analysis of secondary English curriculum policy in Massachusetts, U.S.A. It examines the research questions: How are racial, cultural, and linguistic diversity addressed in secondary English curriculum policy? What beliefs about racial, cultural, and linguistic diversity are reflected in the discourse of secondary English curriculum policy and what are the origins of these beliefs? The English curriculum has been selected for this analysis because in Anglo-dominant societies the subject has served as a conduit for the dominant group's language, history, culture, and values to immigrants (Bloom, 1994; Goodson, 2005; Pinar, 2006). Indeed, the United States holds a distinctive myth in relation to diversity-the melting pot-that emphasizes one unifying culture and language as a necessity for national strength (Gans, 2004; Glazer \& Moynihan, 1970). Historically, immigrants have had to shed their cultures and languages to claim full U.S. citizenship.

A myth is a group's shared heritage that is expressed and handed down to generations through stories. Societies use myths to develop their perspectives on, and practices in relation to, conditions within their society. Myths are patterns of beliefs that give meaning to life. They validate existing social systems, traditional rights, and customs, and they enable individuals and societies to adapt to their environments. Myths shape the cultural identity of a group; resolve cultural dissonance within a society; and provide a framework for moral conduct, social attitudes, and policies (Bierlein, 1994; Leach, 1969; Strauss, 1990). In relation to the dissonance 
resulting from immigration, for example, the myth of the U.S. melting pot has provided a medium for developing social attitudes and policies regarding racial and cultural diversity. As such, this analysis utilizes the melting pot myth to theorize about the origins of the beliefs that shape English curriculum policy pertaining to diversity.

In addition to its use of the melting pot myth, the article employs Michael Apple's $(1980,1993)$ theory of ideological hegemony to examine the beliefs about racial diversity that influence curriculum policymaking. The paper further draws from Basil Bernstein's (1971) social class-based theory of the classification and framing of educational knowledge to analyze the ways in which English curriculum knowledge is selected and distributed. Bernstein's theory is, therefore, extended into the arena of race. The paper further relies on foundational definitions of monocultural and multicultural education to explore distinctions made in policy documents about the literature and languages of different racial, cultural, and linguistic groups. Gillborn (2004) defined monocultural education as educational practices that emphasize and reify Anglocentric knowledge and traditional, testable academic skills over other cultural forms of knowledge. In contrast, multicultural education is a multifaceted yet interrelated set of practices that includes five dimensions: integrating the knowledge and histories of diverse groups into the school curriculum, interrogating the processes by which knowledge is constructed for schools, reducing prejudice, utilizing equity pedagogy to provide all students with equal opportunities to learn, and fostering an empowering school culture (Banks \& Banks McGee, 2001). The paper first presents the theoretical framework and related research on curriculum policy and diversity. Following a discussion of research design and data analysis procedures, it analyzes how the Massachusetts Secondary English Language Arts Curriculum Framework (Massachusetts Department of Education 2001) addresses racial, cultural, and linguistic diversity. The article concludes by considering how curriculum policy may more effectively respond to diversity.

\section{Theoretical Framework and Related Research}

Foundational sociologists of knowledge such as Michael Young and Basil Bernstein, along with scholars of social and cultural reproduction like Pierre Bourdieu, argued that the school curriculum was selected and distributed in ways that maintained power structures in society. Michael Young (1971) viewed curriculum as socially organized knowledge that was selected by those in power from the existing corpus of a society's knowledge base to perpetuate stratification in the wider social structure. From these concepts, Bernstein (1971) developed his theory of the classification and framing of educational knowledge. He proposed that schools delivered distinct types of curriculum knowledge to students of different social classes to prepare them for predetermined adult roles in society. Michael Apple $(1980,1993)$ drew from the ideas of these foundational scholars to theorize that schools constructed official curriculum knowledge through hegemonic processes that reproduced and maintained the dominance of the society's ruling groups. Apple (1980) defined ideological hegemony as the "bourgeois domination of the thought, the common sense, the life-ways, and everyday assumptions of large groups of people in a society...the routine structures of everyday thought and action that helped reproduce class domination and inequality" (p. 60).

\section{The Classification and Framing of Educational Knowledge}

Bernstein (1971) defined classification as the strength of the boundaries between distinct forms of knowledge that were considered either high or low status. Strong classification referred to strong boundaries between high- and low-status knowledge; weak classification implied permeable boundaries. High-status knowledge, Bernstein proposed, is the sacred knowledge of a society and reflects its most abstract, aesthetic, and intellectual ideas. It is the knowledge that represents the histories, values, and norms of the ruling groups of a society and is reserved for the education of their children. Schools prepare these students to occupy the positions of power that have been set aside for them. In contrast, low-status knowledge is considered profane knowledge and is constituted of the everyday, community knowledge of working-class students and their teachers. Schools transmit this form of knowledge to working-class students to prepare them for marginalized roles in society.

The companion concept to classification-framing-referred to the level of independence that teachers and students enjoy in selecting and organizing the content of the curriculum and in determining the pace at which students acquire school knowledge. With strong framing, teachers and students face tightly regulated curriculum, teaching, and achievement mandates. Weak framing provides teachers and students greater freedom to choose their curriculum and pace their own learning. Bernstein (1971) further observed that weak classification and weak framing allowed for greater integration of 
teachers' and students' everyday, community knowledge-although considered profane and low statusinto the school curriculum. Bernstein called this process of incorporating the everyday, community knowledge of students and teachers into the official curriculum "weakening of the educational frame." He argued that the classifications and frames of school knowledge were relaxed, not out of a belief that working-class students' community knowledge was valid school knowledge, but in order to motivate and manage the behaviors of these marginalized students. These working-class students were often disinterested in the esoteric nature of school knowledge, as it reflected the experiences of the dominant group.

Bernstein's (1971) theory of classification and framing conceived of the marginalized groups in society as the working classes. In contemporary Anglo-dominant societies that are racially, linguistically, and socioeconomically diverse, this theory must be extended to include these marginalized populations. This paper considers, then, the classification and framing of curriculum in relation to race, and not just in relation to social class. There are strong parallels between Bernstein's ideas about highstatus knowledge and the Eurocentric and Anglocentric literary canon that reflects the history of the dominant Anglo group (Bloom, 1994). Likewise, low-status knowledge aligns with the hegemonic perception that multicultural literature is valuable primarily because it is motivational for, and intellectually accessible to, minority students who are deemed academically struggling (Skerrett, 2009a).

Indeed, Apple (1993) argued that historically, when official knowledge has included the histories, knowledge, and perspectives of marginalized groups, it has been due to "accords or compromises where dominant groups, in order to maintain their dominance, must take the concerns of the less powerful into account" (p. 11). Such concessions that partially address the demands of subordinate groups are "always fragile, always temporary, and constantly subject to threat" (p. 11). The contests between monocultural and multicultural English curriculum exemplify the complex and contradictory workings of ideological hegemony. Apple (1980) described how hegemonic beliefs and practices can simultaneously support and act against an unequal society. For instance, the influence of multicultural education activists on English language arts curriculum policy is evident in the addition of multicultural texts onto schools' English curricula (Banks, 1986). Nonetheless, there remains a pervasive, hegemonic perception that Eurocentric and Anglocentric literatures are of highest status evidenced by their predominance in advanced English courses. In contrast, multicultural literature is emphasized in lower status ESL classes and in the lower academic tracks, for which students of color are over-selected (Oakes, 2005; Skerrett, 2009a; Skerrett \& Hargreaves, 2008).

Increasing curriculum standardization and highstakes, standardized testing have intensified the hegemonic beliefs and practices of curriculum policymaking and reoriented schools toward Anglocentric knowledge and skills (Freeman, 2005; Gillborn, 2004; Skerrett \& Hargreaves, 2008). Freeman, for example, argued that the 2001 No Child Left Behind Act's (NCLB) discourse of racial color-blindness is a political power move toward reinstating hegemony of the dominant culture. The policy, argues Freeman, aligns with dominant ideologies of individual achievement and social attitudes that support the principle of racial equality. Yet NCLB forgoes concrete measures to address entrenched racial inequality in various social arenas. In its treatment of school as a raceneutral domain that is cordoned off from racial inequalities in the social realm, NCLB represents a hegemonically veiled compromise compared to the broad policy and social moves needed to achieve true racial equality in the United States.

Policies that provide schools and teachers with freedom to select the curriculum are also designed according to hegemonic beliefs — shared by policymakers and educators themselves - that ultimately direct schools' and teachers' curricular choices in particular ways. Lang \& Salas (1998) illustrated the complex political and ideological process involved in implementing multicultural education policy in Michigan that left execution to the discretion of school leaders and teachers. Such weakly framed policies allow educators to embrace fully, partially enact, or altogether bypass policy to the extent that their and their constituents' beliefs, knowledge, and skills align with reforms. Such is the case with Ontario's Anti-racism and Ethnocultural Equity in School Boards (1993) policy that required schools to develop antiracist educational strategies but left conceptualization and implementation to districts. In one district, schools could take up any or all parts of the policy they wished, resulting in wide variation among schools' individual programs (Skerrett, 2008; 2009b). Indeed, as Apple (1980) argued, ideological hegemony works as "complex sets of ideological practices and meanings that set limits back upon our actions and understandings" (p. 60). Theories of the sociology of knowledge applied to curriculum policy expose its race-based and hegemonic nature. 


\section{The U.S. Melting Pot}

What are the origins of the hegemonic beliefs and understandings that influence curriculum policy? As noted earlier, the U.S. melting pot myth has provided a binding narrative about how racial, cultural, and linguistic diversity in society-and attendant dissonance-should be addressed. It bears considering, therefore, whether societal attitudes and structures pertaining to diversity and equality both transmit and maintain particular views about official curriculum knowledge. The U.S. melting pot is a distinctive ideal that emphasizes one unifying national culture and language (Gans, 2004; Glazer \& Moynihan, 1970). As immigration into the United States escalated during the early 1800s and onward, political leaders used the term to shape national perspectives on, and approaches to, ethnocultural diversity (Vought, 2004). The term melting pot originated from the title of a 1908 play written by Israel Zangwill, a Jewish man from England (Gans, 2004). Zangwill penned the historic title, The Melting Pot, to describe burgeoning diversity in the United States and general political and social sentiment about how that diversity should be addressed. Indeed, this play was commissioned by President Theodore Roosevelt . The political and generalized views expressed in the play about increasing diversity encompassed the benefits that the diverse group of immigrants brought to the country, the unparalleled freedoms and opportunities they enjoyed in their new land, and, in consequence, their responsibilities to assimilate into, and thereby advance, the economic, political, and social well-being of both themselves and the United States.

Schools have been prime melting pot sites for culturally and linguistically diverse immigrant students. The curriculum and other educational processes are so aligned with the English language and Anglo culture that it is only those minority students who fully take up the language and culture who reap similar (though rarely identical) educational benefits to their Anglo peers (Lee, 2005). Thus, as Apple (1980) posited, social theories of reproduction are not totally deterministic - there is room for individual agency and resistance. Yet hegemony is at work in this allowance of individual aberrations that maintain the appearance of equal opportunity but leave undisturbed ingrained patterns of social reproduction (Apple, 1970; Bourdieu \& Passeron, 1990). Students who do not or cannot fully take up the English language and Anglo culture are relegated to the lower academic tracks and ESL classes, where the curriculum is more multicultural and motivational in order to prevent their complete disengagement from school (Lee, 2005; Oakes, 2005; Skerrett, 2009a; Skerrett \& Hargreaves, 2008).

As Bernstein (1971) proposed, the educational knowledge frame is weakened to engage and manage students who have been marginalized by school. While he wrote of the working classes, it is evident how, in contemporary U.S. society, the educational knowledge frame is explicitly weakened for racial, cultural, and linguistic minority students. Their official curriculum reflects their multicultural communities and everyday lives, but is assigned low status. This school knowledge is a result of hegemonic accords and compromises (Apple, 1993) that appear responsive to diversity but that simultaneously devalue the knowledge of these less powerful groups. Moreover, increasing student diversity has intensified the melting pot approach in schools in this age of standardization that takes a monocultural approach to education (Skerrett \& Hargreaves, 2008). The impact of the melting pot myth on social attitudes and practices of diversity raises the question of how far this ideal influences the selection of official knowledge for curriculum policy. This analysis takes up such an inquiry.

\section{Data and Method}

Documentary analysis (Miles \& Huberman, 1994) was performed on the Massachusetts English Language Arts Curriculum Framework (2001). Analysis began with an initial stage of iterative reading of policy documents and progressive focusing (Glaser \& Strauss, 2006) to identify, and then closely analyze, sections of the documents where racial, cultural, and linguistic diversity were addressed. Because the research question explicitly focused on curriculum, policy text that addressed other educational practices, such as assessment, were not selected for analysis. After all sections of the policies that concerned diversity and curriculum had been identified and read several times, broad analytic categories were created for the data. These categories derived from the theoretical framework, literature review, and the research question. Categories included, for example, "Multicultural Curriculum" and "Linguistic Diversity." Policy text that identified and discussed literature written by and about the experiences of people of color was assigned to the category of "Multicultural Curriculum." Policy passages that addressed curriculum and language differences were assigned to the category of "Linguistic Diversity." As documents were read and reread, chunks of text, ranging from a single line to a full paragraph, were assigned to these and other broad categories. 
A code list was then developed to conduct deeper analysis of the text placed in each broad category (Miles $\&$ Huberman, 1994). Code names captured emerging themes and reflected the interrelations between the theoretical framework, the literature review, the research question, and what the data revealed. For instance, the code "MCLITLOW" reflected how, in the policy documents, multicultural literature was conceptualized as lower status knowledge than Eurocentric and Anglocentric texts. Policy documents also reflected the influence of the melting pot myth. Hence, a code for melting pot influences on curriculum policy was created-"MELTPOTCURRIC". As codes proliferated, some were combined and others discarded as ongoing reading of the data either continued to provide, or failed to provide, additional evidence. Identically coded data were then assembled into lengthy texts that were read and discussed in memos (Charmaz, 2000). In this way, theoretical and evidentiary claims were derived. Table 1 lists the main themes that emerged from the analysis and briefly summarizes the ways in which the themes revealed themselves in the data.

\section{Limitations of the Research}

The primary limitation of this research is its narrow unit of analysis. The curriculum policy analyzed here pertains to one academic subject and governs one geographic region of the United States. This context possesses its own historical, cultural, and political features. As such,

Table I: Summary of Main Themes

\begin{tabular}{|l|l|}
\hline $\begin{array}{l}\text { Themes From Theoretical } \\
\text { Framework }\end{array}$ & Evidence of Themes in the Data \\
\hline Classification of the Curriculum & Strong \\
\hline Framing of the Curriculum & Weak at a surface level but strong in practice \\
\hline High-Status Knowledge & Eurocentric and Anglocentric literature \\
\hline Low-Status Knowledge & Multicultural and contemporary literature \\
\hline $\begin{array}{l}\text { Weakening of the Educational } \\
\text { Knowledge Frame }\end{array}$ & $\begin{array}{l}\text { Evident through the additive approach to } \\
\text { multicultural and contemporary literature }\end{array}$ \\
\hline Ideological Hegemony & $\begin{array}{l}\text { Evident; multicultural literature and diverse } \\
\text { languages valued, yet Eurocentric and } \\
\text { Anglocentric literature and the English language } \\
\text { afforded higher status }\end{array}$ \\
\hline Melting Pot Myth & $\begin{array}{l}\text { Evident; English language fluency considered } \\
\text { essential for academic excellence and full U.S. } \\
\text { citizenship; Eurocentric and Anglocentric } \\
\text { literature key to assimilation of immigrant } \\
\text { students. }\end{array}$ \\
\hline
\end{tabular}

the findings of this research cannot be automatically applied to other contexts without thorough consideration of their unique cultural and policy conditions. The importance of this research and its findings lies in the model it provides of how to uncover and carefully examine the implicit assumptions that undergird curriculum policy. Analyses of this kind facilitate determinations about whether a policy's stated beliefs, processes, and goals are reconcilable with its unstated perspectives. These explorations are essential for curriculum policymakers, who must examine their beliefs to understand how such beliefs affect policymaking. Such critical examinations are also crucial for school leaders and teachers who need to take a critical approach to policies that influence their beliefs about knowledge, teaching, and students and that direct their educational practices.

\section{Results}

The Massachusetts English Language Arts Curriculum Framework (Massachusetts Department of Education 2001, 2004), which regulated the content and structure of English curricula throughout the state, replaced the 1997 framework. The new framework was part of several documents created to "advance educational reform," as noted in the 2001 preamble, in the mid- to late 1990s in Massachusetts. In the preamble to the 2001 document, the commissioner of education wrote that the state had decided to leave the 1997 secondary English curriculum standards virtually intact "in order to keep expectations consistent for the grade 10 English language arts assessment." This reference to the grade 10 English assessment pertained to the introduction in 1998 of a high-stakes (state graduation requirement) standardized test in the English language arts that was a key component of the state's educational reform agenda. Additionally, in 2004, the state declined to change its secondary English standards when it revised the standards for grades three, five, and seven (Massachusetts Department of Education, 2004). It chose instead to maintain its course on preparing secondary teachers and students for success on the standardized test. 
The state's English curriculum policy was created by Department of Education staff who had then invited the feedback of "teachers, administrators, and specialists" on the draft. The department had then "unified their ideas" in finalizing the policy. The description of policy development implied an open and recursive process that involved teachers and other educational stakeholders. However, analysis suggested that development of the framework occurred in a somewhat controlled manner and left many unanswered questions about the ideologies of the creators of this policy. The process of determining which "teachers, administrators, and specialists" would be invited to comment on the drafts was unclear as was the extent to which their feedback was incorporated in final revisions of the document. The development of this curriculum policy appeared, therefore, to align with hegemonic practices, as described by Apple (1993), in which those in positions of power-policymakers-ultimately decided what would count as official knowledge. The department's pointed statement that it had solicited feedback from, and integrated the ideas of, teachers and "specialists," operated as another hegemonic device. This declaration sought to legitimize the educational validity of the document, garner for it widespread public support, and ensure educators' assent to, and use of, the framework. The statement drew on the routine meanings and understandings held by educational stakeholders that the policy document had been developed and approved by the classroom teachers who were to implement it. Moreover, the remark suggested that the process was overseen by an intellectual bourgeoisie of "specialists" who ensured its educational soundness.

In accordance with ideological hegemony, there were no explicit and rigid mandates from the department about how schools were to use this framework to guide their curriculum and instruction. However, because the document emphasized that the framework had been developed to align with the state graduation test, this ensured that all schools and teachers worked from, or at least consulted, the documents when selecting their curriculum. Thus, teachers' actions were directed by the implicit meanings and purposes of the policy document. While there were no strict guidelines for using the document, compliance was assured as schools and teachers labored under the pressures of the state's high-stakes test. It was ironic, then, that in collegial discourse, the commissioner of the Department of Education addressed each teacher individually in his introductory remarks to the 2001 framework: "I encourage you to read this doc- ument with your colleagues and to work with it as you develop units and lessons for your classrooms. This framework offers you a comprehensive tool for planning your English language arts curriculum."

\section{Classification and Framing of the Secondary English curriculum in Relation to Race}

The framework was organized according to ten guiding principles, or "philosophical statements [that] guide[d] the construction and evaluation of English language arts curricula" (p. 3). These guiding principles articulated the department's "beliefs about the teaching, learning, and assessing of speaking, viewing, listening, reading, and writing" (p. 3) in the English language arts. The framework organized the English language arts into four strands-language, reading and literature, composition, and media. There were, as well, general standards with accompanying rationales "that outline[d] what students should know and be able to do" (p. 3) in each grade. The framework further provided numerous "learning scenarios"- examples of how each learning standard could be addressed in the classroom. Analysis of the state's English curriculum framework pointed to strong classification combined with strong framing, although at its surface level, policy discourse suggested weak framing. Taken at face value, the policy was weakly framed in its espousal of an integrated view of literacy and writing across the curriculum. The policy also seemed weakly framed in affording a measure of latitude to schools and teachers in selecting literature that best suited their students' needs.

State policy resembled weak framing, as well, in relation to the selection of knowledge. Students were to read from a wide variety of literary sources that included classical and contemporary literature as well as informational and media texts. The framework also appeared to be permissive rather than prescriptive, in that it provided exhaustive recommendations of "suggested," but not required, authors of both classical and contemporary works. Additionally, the state purposely avoided disaggregating the lists of authors by grade level, due to the "recognition that teachers should be free to choose selections that challenge but do not overwhelm their students" (p. 99). Yet the document also stated that "a comprehensive literature curriculum contains works from both [classical as well as contemporary] lists" (p. 4). Therefore, in practice, choice of texts was constrained because schools' curricula were, to some degree, expected to reflect the classical and contemporary listings. Close analysis of the policy, therefore, revealed stronger framing than might have been first assumed. As sociolo- 
gists of knowledge have described, deeply entrenched cultural notions held by parents and teachers about "what counts" as valid school knowledge, the university tradition that privileges Eurocentric and Anglocentric literature, school budgets, and standardized testing operate as hegemonic understandings beneath the surface of weakly framed policy (Apple, 1993). These beliefs ensure that teachers and students are governed by strong frames in relation to the texts they study. In the English language arts, these texts typically derive from the historic Western canon (Bloom, 1994).

Not only was state policy strongly framed, it was also strongly classified in relation to race-related content. The policy documents conceived of high-status literary knowledge as classic texts from the Western tradition and advocated that this body of literature form the foundation of students' literature studies. The framework proclaimed that "American students need to become familiar with works that are part of a literary tradition going back thousands of years. Students should read literature reflecting the literary and civic heritage of the English-speaking world" (p. 4). The framework then erected strong boundaries between such high-status knowledge and multicultural and contemporary literature, which were presented as lower status knowledge. These conceptual boundaries were exemplified and embodied by the creation of two separate lists of literature in the appendices of the documents. One list, Appendix A, contained canonical Eurocentric and Anglocentric texts. The other list, Appendix B, comprised authors of multicultural, international, and contemporary literature. While the list of authors in Appendix A—the classical category-was said to reflect "our common literary and cultural heritage" (p. 4), the writers concerned were primarily of white U.S., British, or European origin. This list also included Greek mythology and drama and the Bible. No works originally written in languages other than English were included besides these translated canonical works.

Scholars have theorized about issues of translation in the teaching of world literature (Carroll, 1996; Mollenkott, 1990; Rado, 1987; Tymoczko, 1995). There was, however, no discussion in the framework of what criteria might be used in selecting translations of texts that were originally written in languages other than English. Neither were teachers asked to consider what it meant for students to receive texts that were created in a language other than English, and in another culture, as a part of the Western canon. Translated into the English language, these texts were subtly credited to, and appro- priated by, Anglo culture (Carroll, 1996). Such explicit conversations are needed to demonstrate to students the intellectual and aesthetic worth of all world languages. These discussions help expose and disrupt hegemonic beliefs that the English language is best suited for literary expression.

The English-speaking literary legacy was juxtaposed with "works from the many communities that make up contemporary America as well as from countries and cultures throughout the world" (p. 4). The framework thus embodied an oppositional conception of Eurocentric and Anglocentric literature on one hand, and contemporary, multicultural, and world literature on the other. Students were expected to receive "broad exposure" to contemporary, multicultural, and world literature, implying breadth over depth when studying them. Although they were marginalized in this curriculum policy, literary scholars have cited the value of teaching such texts. Multicultural and world literature introduces conversations about the diverse and complex meanings to be made of literature as it traverses time, space, and cultures, and incorporates the perspectives, experiences, and identities of numerous writers and readers (Stephanides, 2004). Students develop their imaginations about universal communication and a shared humanity when they study world literature (Pheng, 2008). Studying world literatures encourages teachers and students to raise questions about why texts from particular cultures, over time, get taken up into a canon of literature yet those from other cultures do not (Tymoczko, 1995). These rich and necessary learning opportunities were not emphasized in policy documents. Instead, the policy positioned diverse literatures as ancillary to Eurocentric literature which retained its central role in the English curriculum. In this way, the State weakened the educational knowledge frame by supplementing Eurocentric literature with racially and culturally diverse literature.

Additional, striking evidence of this weakening of the educational knowledge frame with race-related content was noted in a separate section of the framework titled "Immigrant Experience." Here, the framework suggested writings from immigrants from Europe, Asia, the Caribbean, and Central and South America. Grouped with these authors were "the experiences of Native Americans and slave narratives [such as] Harriet Jacobs" (p. 104). The assignment of just three lines to literature about the immigrant experience exemplified the marginalization of literature about immigrant groups. Further, inclusion of works by Native Americans and African 
slaves in the immigrant section betrayed a gross error of judgment, for these groups of people cannot be considered "immigrants" to the United States by any standard or criterion.

As these policy documents demonstrated, the educational knowledge frame is weakened not only along lines of social class, as Bernstein (1971) proposed, but also along lines of race. The state weakened the educational knowledge frame with its direction to teachers that multicultural and world literature provide students with "broad exposure" to the diversity of the world as expressed in literature. Weakening of the educational knowledge frame occurred through the study of racially and ethnoculturally diverse texts that were considered lower status, community-oriented, and everyday knowledge. Students were to engage with these forms of literature only after they had been thoroughly immersed in the study of the Eurocentric and Anglocentric canon. Apple (1980) cautioned that "no assemblage of ideological practices and meanings and no set of social and institutional arrangements can be totally monolithic," that although "powerful ideological forces aim toward reproduction," there will be "countervailing tendencies and oppositional practices going on as well" (p. 60). Resistance to hegemonic ideology was evidenced in the inclusion of multicultural literature in the policy documents. Yet this integration occurred in "inherently contradictory and relatively disorganized" (p. 60) ways that failed to disrupt the more powerful ideological beliefs that reproduce social and racial inequality in the curriculum.

\section{Melting Pot Influences on English Curriculum Policy}

The framework revealed numerous influences of melting pot ideology that helped explain the strong boundaries that existed between the "high-status" Western canon and "low-status" culturally diverse literature. For example, Guiding Principle 8 of the framework provided evidence of the melting pot approach to immigrant students and those outside the dominant "English-speaking" cultural heritage.

Teachers recognize the importance of being able to respond effectively to the challenges of linguistic and cultural differences in their classrooms. They recognize that sometimes students have learned ways of talking, thinking, and interacting that are effective at home and in their neighborhood, but which may not have the same meaning or usefulness in school. Teachers try to draw on these different ways of talking and thinking as potential bridges to speaking and writing in standard English (p. 5).

This principle commenced with a statement that valued the various home languages, experiences, and interests that students bring to school: "An effective English language arts curriculum builds on the language, experiences, and interests that students bring to school" (p. 5). Further reading, however, revealed that these differences were considered "challenges" for teachers. The framework claimed that although students' diverse ways of speaking, thinking, and communicating "are effective at home and in their neighborhood," they "may not have the same meaning or usefulness in school" (p. 5). Bernstein (1971) and others have outlined the disjuncture that exists between many students' home linguistic discourses and cultures and the Anglo linguistic and behavioral codes of the school. However, the state privileged the dominant language as more useful to intellectual enterprise than other tongues. Further, the framework did not judge monocultural language instruction to be problematic and in need of change. Rather, minority students' languages and cultures, true to the melting pot ideology, needed to convert to, and align with, the dominant culture and language to ensure academic success. Teachers were advised that students' linguistic and cultural differences might be "potential bridges" to their mastery of Standard English. Yet the very use of the word "potential" cast doubt on whether languages other than English could be entrusted with transporting students safely out of their linguistic communities into the Standard English-speaking world.

Given these beliefs, it is not surprising that the policy documents omitted discussion about the original languages and cultural contexts of world literatures. Apple (1980) has argued that "side by side with beliefs and actions that maintain the dominance of powerful classes and groups, there will be elements of serious (though perhaps incomplete) understanding, elements that see the differential benefits and penetrate close to the core of an unequal reality" (p. 61). The state apprehended that educational inequity results from differences between the dominant language and culture of the school and those of diverse student groups. It displayed a serious, though incomplete, understanding of how to address cultural and linguistic differences effectively. In reverting to the melting pot ideology that requires adoption of English and the dominant culture for full educational access and success, the state perpetuated the dominance of the Anglo group in U.S. society. 
Still more evidence of an assimilationist perspective was found in Guiding Principle 10:

While encouraging respect for differences in home backgrounds, an effective English language arts curriculum nurtures students' sense of their common ground as present or future American citizens in order to prepare them for responsible participation in our schools and in civic life (p. 6).

This discourse implied that the English curriculum possessed the capability to develop in students an "American-ness" that was defined in terms of commonality and not difference. Who was this "American" citizen? He or she was not linguistically or culturally different from the English heritage. Any variations from the Anglo norm needed to be melted away before full U.S. citizenship could be attained, with all of its attendant responsibilities in "our" schools and civic life. Great power was assigned to the study of literature in the assumption that it could accomplish these goals.

Teachers instruct an increasingly diverse group of students [who] may come from any country or continent in the world. Taking advantage of this diversity, teachers guide discussions about the extraordinary variety of beliefs and traditions around the world. At the same time, they provide students with common ground through discussion of significant works in American cultural history to help prepare them to become self-governing citizens of the United States of America. An English language arts curriculum can serve as a unifying force in schools and society (p. 6).

Indeed, historically, English has been used as a core subject to transmit national and cultural values and to secure hegemony (Goodson, 2005; Pinar 2006). In line with this long tradition, the state's English framework expressed the view that the unification of diverse groups in the melting pot of the school should and could occur solely through the study of "significant works in American cultural history."

\section{Concluding Discussion with Implications for Educational Policy}

This analysis has applied and extended foundational social class-based theories about the sociology of school knowledge into the arena of race. Using this extended theory along with the national cultural myth of the U.S. melting pot, this paper has exposed how deep-seated race-based notions about official knowledge shape cur- riculum policy. In the English curriculum policy analyzed here, the Eurocentric and Anglocentric canon, the English language, and Anglo culture were granted high status. In contrast, multicultural literature, languages other than English, and diverse cultures were demoted to the category of low status. Through the use of explicit language and measures, or otherwise more implicit hegemonic discourse, teachers and students were regulated by strong classification and frames that directed them toward extensive study of the Western canon and more limited engagement with diverse curricula. Students' diverse languages and cultures were not valued as intrinsically worthy of academic study. Instead, their languages and cultures were to be drawn upon to melt them into conformance with the dominant language and culture. In these ways, weakening of the educational knowledge frame occurred in curriculum policy in relation to racerelated content.

\section{Recommendations for Educators and Curriculum Policy Makers}

Curriculum policy that relies on hegemonic discourse to perpetuate racial stratification of knowledge necessitates that school leaders and teachers develop the critical skills and social justice-oriented attitudes to decipher and disrupt these patterns. Educators also need political, financial, and educational resources to design and implement culturally inclusive and socially critical curriculum and schooling processes. For example, some diverse districts and individual schools have had the backing of philanthropic foundations, university partnerships, local community groups, or committed local leadership. With these resources and partnerships, they developed professional learning communities where school leaders and teachers inquired into multicultural and social justice teaching. Some also implemented alternative learning structures, such as small learning communities that stressed high-quality teaching, inclusive curricula, and multiple forms of assessments (Dentler \& Hafner, 1997; Oakes, Hunter Quartz, Ryan, \& Lipton, 2002; Oakes \& Rogers, 2006; Philadelphia School Reform Commission, 2005; Reyes, Scribner, \& Scribner-Paredes, 1999). School leaders and teachers attempting to create learning environments that are responsive to diversity can look to these inspiring examples.

However, internal strategies for responding to diversity must ultimately be accompanied by external policy support if they are to last and spread (Goodson, 2001; Sarason, 1990). Here, the most important area for external change pertains to moving beyond existing strategies 
of curriculum prescription toward post-standardization (Hargreaves \& Shirley, 2008). Post-standardization provides greater flexibility for teachers to be creative and innovative in responding to diverse student needs. Indeed, England, Wales, parts of Canada, and other countries are now moving in this direction (Fullan, Hill, \& Crevola, 2006; Welsh Assembly Government, 2006; Hopkins, 2007). In reaction to the educational results and economic performance of other countries, the influential U.S. authors of Tough Choices or Tough Times? (National Center on Education and the Economy, 2007) argue against the excesses of standardization in favor of a more creative curriculum taught by highly qualified teachers in order to raise standards and equalize outcomes among all students. The international movement, then, is toward more weakly classified and framed curriculum policy. In departure from a melting pot ideology, such policies allow schools and teachers to develop highquality curricula that are responsive to the diverse backgrounds and learning needs of the students they serve. With these weaker classifications and frames, as argued earlier, come educator responsibilities to develop the knowledge, skills, and commitments to design and implement racially equitable curriculum and other schooling processes.

The argument proposed and explored in this paper is that cultural myths regarding diversity influence social attitudes as well as educational policy. This argument has also been suggested by Carrington \& Bonnett (1997) who argued that Canada's mosaic myth, which emphasizes the equal value and acceptance of all cultures and ethnicities, provided a model for Canadians about how they should view and practice diversity. This myth, the authors maintain, created fertile ground for the development and implementation of Ontario's antiracist education policy in 1993. Therefore, myth affects as well as reflects social attitudes and policy responses to diversity. For the United States, this is a promising proposition. In recent national polls (Gallup Organization, 2004a, b), U.S. citizens, particularly those of younger generations, claimed to be replacing the ideal of the melting pot with more pluralistic perspectives on racial diversity. The growing international policy movement toward poststandardization that is beginning to influence the United States, along with these more inclusive attitudes toward diversity, breeds optimism. These trends raise doubts about the degree to which the melting pot myth will reflect or influence future educational policy, practices, and beliefs in relation to diversity.

\section{References}

Apple, M. W. (1980). Analyzing determinations: Understanding and evaluating the production of social outcomes in schools. Curriculum Inquiry, 10(1), 55-76.

Apple, M. W. (1993). Official knowledge: Democratic education in a conservative age. New York: Routledge.

Banks, J. A. (1986). Multicultural education: Development, paradigms and goals. In J. A. Banks \& J. Lynch (Eds.), Multicultural education in western societies (pp. 2-28). New York: Praeger Publishers.

Banks, J. A., \& Banks McGee, C. A. (2001). Handbook of research on multicultural education. San Francisco: Jossey-Bass.

Barrell, B. R. C., Hammett, R. F., Mayher, J. S., \& Pradl, G. M. (2004). Teaching English today: Advocating change in the secondary curriculum. New York: Teachers College Press.

Bernstein, B. (1971) Class, codes and control. Volume I: Theoretical studies towards a sociology of language. London: Routledge \& Kegan Paul.

Bierlein, J. F. (1994). Parallel myths. New York: Ballantine.

Bloom, H. (1994). The western canon: The books and school of the ages. New York: Riverhead Books.

Bourdieu, P., \& Passeron, J. (1990). Reproduction in education, society and culture. 2nd ed. Thousand Oaks, CA: Sage.

Carrington, B., \& Bonnett, A. (1997). The other Canadian "mosaic": "Race" equity education in Ontario and British Columbia. Comparative Education 33(3), 411-431.

Carroll, M. T. (Ed.). (1996). No small world: Visions and revisions of world literature. Urbana, IL: National Council of Teachers of English.

Charmaz, K. (2000). Grounded theory: Objectivist and constructivist methods. In N. Denzin and Y. Lincoln (Eds.), Handbook of Qualitative Research. (2nd ed., pp. 509-535). Thousand Oaks, CA: Sage Publications.

Dentler, R. A., \& Hafner, A. L. (1997). Hosting newcomers: Structuring educational opportunities for immigrant children. New York: Teachers College Press.

Freeman, E. (2005). No Child Left Behind and the denigration of race. Equity and Excellence in Education, 38(3), 190-199.

Fullan, M., Hill, P., \& Crevola, C. (2006). Breakthrough. Thousand Oaks, CA: Corwin Press. 
Gallup Poll Organization. (2004a). Few Americans feel day-to-day racial tension. Retrieved December 11, 2007 from http://www.gallup.com/poll/12883/FewAmericans-Feel_DaytoDay-Racial-Tension.aspx

Gallup Poll Organization (2004b). Should minorities blend in or stand out? Gallup Poll Tuesday Briefing. Retrieved December 12, 2007 from http://www.gallup.com/poll/12259/ShouldMinorities-Blend-Stand-Out.aspx

Gans, H. J. (2004). The American kaleidoscope, then and now. In T. Jacoby (Ed.), Reinventing the melting pot: The new immigrants and what it means to be American (pp. 33-46). New York: Basic Books.

Gillborn, D. (2004). Antiracism: From policy to praxis. In G. Ladson-Billings \& D. Gilborn (Eds.). The RoutledgeFalmer Reader in Multicultural Education. (pp. 35-48). London: RoutledgeFalmer.

Glaser, B. G., \& Strauss, A. L. (2006). The discovery of grounded theory: Strategies for qualitative research. Chicago: Aldine Publishing Co.

Glazer, N., \& Moynihan, P. (1970). Beyond the melting pot. Cambridge, MA: MIT Press.

Goodson, I. F. (2001). Social histories of educational change. International Journal of Educational Change, 2(1), 45-63.

Goodson, I. F. (2005). Bringing English to order: Learning, curriculum, and life politics: The selected works of Ivor F. Goodson. London: Routledge.

Hargreaves, A., \& Shirley, D. (2008). Beyond standardization: Powerful new principles for improvement. Phi Delta Kappan, 90(2), 135-143.

Hopkins, D. (2007). Every school a great school: Realizing the potential of system leadership. London: Open University Press.

Kertzer, D. I. (1988). Ritual, politics, and power. New Haven: Yale University Press.

Lang, M., \& Salas, G. (1998). Multicultural education in Michigan's public schools: Policy and practice. Equity \& Excellence in Education, 31(3), 64-72.

Leach, E. (1969). Genesis as myth and other essays. London: Jonathan Cape.

Lee, S. J. (2005). Up against whiteness: Race, school, and immigrant youth. New York: Teachers College Press.

Massachusetts Department of Education. (2001). Massachusetts English language arts curriculum framework 2001. Retrieved November 15, 2004 from http://www.doe.mass.edu/framework/ela/0601.pdf
Massachusetts Department of Education. (2004). Supplement to the Massachusetts English language arts curriculum framework. Grades 3, 5, and 7. Grade level standards for vocabulary, reading, and literature.

Retrieved September 26, 2009 from http://www.doe.mass.edu/frameworks/ela/0504sup. pdf

Miles, M. B., \& Huberman, M. (1994). Qualitative data analysis: An expanded sourcebook. 2nd ed. Thousand Oaks, CA: Sage Publications.

Mollenkott, V. R. (1990). Critical inquiry and biblical inerrancy: Suggestions for class discussion. Religion and Public Education, 17(1), 79-88.

National Center on Education and the Economy. (2007). Tough choices or tough times: The report of the new commission on the skills of the American workforce. San Francisco, CA: Jossey Bass.

Oakes, J. (2005). Keeping track: How schools structure inequality. New Haven, CT: Yale University Press.

Oakes, J., Hunter Quartz, K., Ryan, S., \& Lipton, M. (2002). Becoming good American schools: The struggle for civic virtue in education reform. San Francisco, CA: Jossey Bass.

Oakes, J., \& Rogers, J. (with Lipton, M.) (2006). Learning power: Organizing education and justice. New York: Teachers College Press.

Ontario Ministry of Education and Training. (1993). Anti-racism and ethnocultural equity in school boards. Retrieved September 26, 2009 from http://www.edu.gov.on.ca/eng/document/curricul/an tiraci/antire.pdf

Pheng, C. (2008). What is a world? On world literature as world-making activity. Dedalus, 137(3), 26-38.

Philadelphia School Reform Commission. (2005). Retrieved November 13, 2007 from http://www.phila.k12.pa.us/src/

Pinar, W. (2006). Race, religion, and a curriculum of reparation: Teacher education for a multicultural society. New York: Palgrave MacMillan.

Rado, G. (1987). A typology of LLD translation problems. International Journal of Translation, 33(1), 613.

Reyes, P., Scribner, J. D., \& Scribner-Paredes, A. (1999). Lessons from high-performing Hispanic schools: Creating learning communities. New York: Teachers College Press. 
Sarason, S. B. (1990). The predictable failure of school reform: Can we change course before it's too late? San Francisco, CA: Jossey-Bass.

Skerrett, A. (2008). Racializing educational change: Melting pot and mosaic influences on educational policy and practice. Journal of Educational Change, 9(3), 261-280.

Skerrett, A., \& Hargreaves, A. (2008). Student diversity and secondary school change in a context of increasingly standardized reform. American Educational Research Journal, 45(4), 913-945.

Skerrett, A. (2009a). Responding to student diversity amidst tested traditions and testing standards. Teaching Education, 20(3), 277-290.

Skerrett, A. (2009b). Biographical orientations to secondary English teaching within a mosaic context of diversity. English Education, 41(3), 281-303.

Sloan, K. (2006). Teacher identity and agency in school worlds: Beyond the all-good/all-bad discourse on accountability-explicit curriculum policies. Curriculum Inquiry, 36(2), 119-152.

Strauss, C. (1990) Who gets ahead? Cognitive responses to heteroglossia in American political culture. American Ethnologist, 17(2), 312-28.

Stephanides, S. (2004). Translatability of memory in an age of globalization. Comparative Literature Studies, 41(1), 101-115.

Suarez-Orozco, M. M. (2001). Globalization, immigration and education: The research agenda. Harvard Educational Review, 71(3), 345-365.

Tymoczko, M. (1995). The metonymics of translating marginalized texts. Comparative Literature, 47(1), 11-25.

Vought, H. P. (2004). The bully pulpit and the melting pot. Macon, GA: Mercer University Press.

Welsh Assembly Government. (2006). Curriculum and assessment. Retrieved August 14, 2007 from

http://new.wales.gov.uk/topics/educationandskills/curriculum_and_assessment/?lang=en.

Young, M. F. D. (Ed.). (1971). Knowledge and control: New directions for the sociology of education. London: Routledge and Kegan Paul.

\section{Notes}

1. In this section, all references to, and quotations from, the framework derive from the Massachusetts English Curriculum Framework (2001).

IJEPL is a joint publication of the Association for Supervision and Curriculum Development, the Faculty of Education at Simon Fraser University, and the College of Education and Human Development at George Mason University. By virtue of their appearance in this open access journal, articles are free to use, with proper attribution, in educational and other non-commercial settings 90 days after initial publication. Copyright for articles published in IJEPL is retained by the authors. More information is available on the IJEPL Web site: http://www.ijepl.org 